\title{
Guanine Deaminase Measurement
}

National Cancer Institute

\section{Source}

National Cancer Institute. Guanine Deaminase Measurement. NCI Thesaurus. Code C150845.

The determination of the amount of guanine deaminase present in a sample. 